\title{
COVID-19 Wake-up Call: Equity or Else
}

COVID-19 is neither the first, last, nor the worst pandemic we will face as a species. Novel zoonoses will continue to develop and spread as the climate shifts, ecosystems contract and habitats overlap. It is entirely possible that history will categorize the COVID-19 pandemic as a 'starter plague.' Our hyper-connected, yet increasingly fragmented world is a petri dish ripe for viral mutation and transmission-international travel happens overnight, mismatched and poorly prioritized health and safety regulations lend themselves more to chaos than cures, and nationalist policies foster both festering global viruses and expanding socioeconomic inequities.

The underlying issue is indeed inequity: too many societies prize wealth and comfort for a few over the health and welfare of the many, or even of the planet itself. It explains why those who are marginalized in society have higher rates of disease and death from COVID-19; why some health systems appear to manage while others become overwhelmed with shortages of personnel, beds and even oxygen; and why entire countries and communities have higher vaccination rates than others.

The epidemiology of COVID-19 does not reflect a consensus that we are 'all in this together,' but rather that some people seem to be predestined targets of the disease. We are living through what several scientists have called a syndemic...in this case, the combined effects of negative social determinants, inadequate or nonexistent access to health services, depleted and pauperized public health facilities, poorly protected and unevenly allocated health workers, and finally scarce vaccine availability. Without a sharp and immediate increase in aid to developing countries, it is estimated that some 150 million more people will be pushed into extreme poverty.

If you take Latin America and the Caribbean as a whole-with the United States, it is the epicenter of the current surge in cases and deaths-you will find a region that not only remains the world's most inequitable, but one that has experienced the most serious economic and social crisis in recorded history, with some economies shrinking by nearly $8 \%$. As a result, last year an additional 22 million people in the region were plunged into poverty, a number now exceeding 209 million in total. These people are among those most at risk when it comes to COVID-19; their already precarious lives shortened by lack of health services and slow vaccine rollout.

Like their US neighbor to the north, most of these countries have fragmented health systems, services divided between private and public providers, with private insurers challenging physicians for the 'right' to determine what to prescribe and how to treat. Most, with the exception of Cuba and a few others, invest less than 4\% of GDP in health care, and do not ensure medical services for all their people, much less medical care on equal terms. In the context of COVID-19, the universal health imperative looms larger than ever, turning a long-term goal into an urgent, practical matter.

As the global pandemic surge multiplies cases and deaths, the equity of vaccine rollout also looms large. Newly reported evidence suggests that vaccine effectiveness is only half the

battle. In fact, a recent study indicates that "a vaccine with $65 \%$ and $60 \%$ efficacy before and after the variants, respectively, can outperform a vaccine with $95 \%$ and $90 \%$ efficacy, if its distribution is $46 \%$ to $48 \%$ faster."[1] And of course the reverse is also true. Unfortunately, COVID-19 vaccine availability now is a byproduct of a big pharma industry that for decades has been more focused on vaccine profitability, thus contributing to vaccine nationalism in both R\&D and sales.

\section{We are far from the time when Jonas Salk refused to patent his polio discovery, for fear that children's lives would be sacrificed on the altar of profit.} vaccines in some countries... and communities... while others are kept in limbo, left in purgatory for another two to three years before their 'turn' comes around. In the end, the world is billions of vaccines short, and new variants threaten to outpace even the most effective vaccines.

In the case of Cuba, the COVID-19 syndemic has become a 'sandemic,' with the added punitive inequity imposed by US sanctions. Despite the change in administration and despite the annual, overwhelming vote by UN member states against this US embargo (deemed a 'blockade' by Cubans); despite the fact that Cuban scientists have produced at least two promising vaccine candidates that they have pledged to make available to other developing countries, US policy is stuck in the past. Cuba, according to Washington, is 'not a priority.' Granted, police violence against people of color, mass shootings, systemic racism, the flood of immigrants fleeing exacerbated poverty and violence, and COVID-19 itself: all are public health emergencies. But so, we would argue, are the lives of 11 million Cubans currently hanging in the balance, still suffering from the Trump era's 242 additional measures tightening the screws. When will they become a priority? When will US sanctions on Cuba become a public health issue? A human rights issue?

\section{When will US sanctions on Cuba become a public health issue? A human rights issue?}

The global clock is ticking, the cases of COVID-19 are mounting, the deaths continue. The pandemic is indeed a moment of reckoning. Rather than punishing a small island country, perhaps we should take a closer look at Cuba, since even in dire circumstances, their rates of illness and death from the pandemic are still a tiny fraction of those in other countries of the region and in the USA itself. Perhaps the takeaway from the Cuban COVID-19 experience is that universal health care may be one of the best investments a society can make.

Which brings us to the journal's current issue. As has been the case for the past year, many of the following pages are devoted to the COVID-19 pandemic. Two articles cover the toll COVID-19 has exerted on mental health and our collective psyche; in Lessons from the Field, Fabelo and colleagues delve into the complications the pandemic has caused for treatment maintenance 
in patients undergoing therapy for addiction, while an article by Patricia Áres confronts the strangeness that is 'pandemic time.'

Two Viewpoints warn of COVID-19's aftershocks: the first, by Broche and Medina, addresses the neurological and cognitive sequelae of the disease, using preliminary evidence to call for longitudinal studies of patients suffering from persistent, or 'long-haul' illness. The second, by Ley, alerts pediatricians the world over, suggesting that cardiovascular damage in children afflicted by the SARS-COV-2 virus is likely under-reported-an issue of undeniable importance as new variants affect more children worldwide.

Of increasing clinical import, a systemic review by Suárez and Villegas examines the links among aging, chronic disease and the immunopathological progression of the SARS-CoV-2 virus, associating severe clinical manifestations of COVID-19 to lowgrade chronic inflammation.

MEDICC Review reiterates our call to Latin American and Caribbean population health, medical and planetary health authors to consider submitting their work to our journal, in English or Spanish. You are the reason we publish. - 1 -

\section{-The Editors}

1. Kim D, Keskinocak P, Pekgün P, Yildrim I. The balancing role of distribution Speed against varying efficacy levels of COVID-19 vaccines under variants. medRxiv [Preprint]. 2021 Apr 13 [cited 2021 Apr 20]. Available at: https://www .medrxiv.org/content/10.1101/2021.04.09.21255217v1

\section{In Memoriam}

\section{MEDICC Review dedicates this issue to}

\section{Gustavo Sierra-González MD PhD}

(1952-2021)

A loss for Cuba, Latin America and the world: immunologist and biotechnology pioneer Dr Gustavo Sierra has died from complications of COVID-19. An initiator of Cuba's biotechnology takeoff in the late 1980s, he was a founder of the Finlay Vaccine Institute and the Genetic Engineering and Biotechnology Center, as well as among the first leaders of the BioCubaFarma conglomerate and the first President of the Cuban Society of Immunology. At the time of his death, he chaired the Expert Committee of Cuba's National Immunization Program and served as Advisor to the President of BioCubaFarma.

Credited to Dr Sierra is authorship of the world's first effective vaccine against serogroup B meningococcal disease in 1989, a patent for which his team won the World Intellectual Property Organization's Gold Medal. Earlier, he was among the researchers who obtained Cuba's first interferons.

These accomplishments, together with his later work on a host of other vaccines, earned him the country's highest award, the Carlos J. Finlay Order, as well as honors from the Health and Science Workers Union and distinguished membership in the Cuban Academy of Sciences.

He was advisor to some 45 doctoral dissertations, among his responsibilities as teacher, mentor and guide to generations of physicians, scientists and scholars.

Dr Sierra was a peer reviewer and author for MEDICC Review, his most recent manuscript published in 2019 recounting the history and use of the meningitis B vaccine in Cuba and the world (Cuban Meningococcal Vaccine VA-MENGOC-BC: 30 Years of Use and Future Potential).

He was appreciated and loved by his family and so many others for his modesty, wisdom, good humor and boundless solidarity.

Our editors have lost a friend and colleague. The world has lost a vaccine hero. 